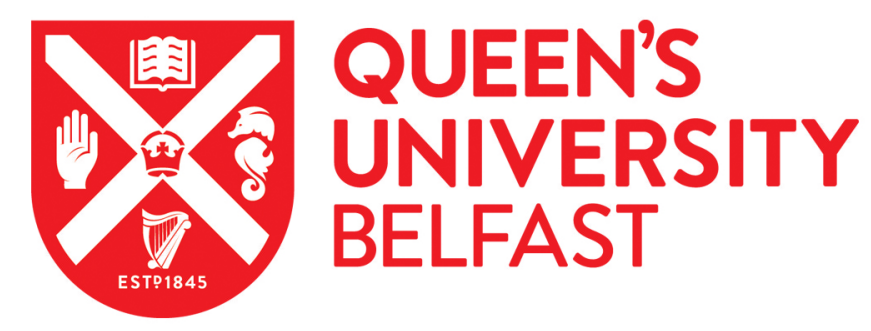

\title{
Built environment correlates of overweight and obesity among adults in Chennai, India
}

Adlakha, D., Brownson, R. C., \& Hipp, J. A. (2020). Built environment correlates of overweight and obesity among adults in Chennai, India. Cities and Health. https://doi.org/10.1080/23748834.2020.1791397

\section{Published in:}

Cities and Health

\section{Document Version:}

Peer reviewed version

Queen's University Belfast - Research Portal:

Link to publication record in Queen's University Belfast Research Portal

\section{Publisher rights}

Copyright @ 2020 Informa UK Limited, trading as Taylor \& Francis.

This work is made available online in accordance with the publisher's policies. Please refer to any applicable terms of use of the publisher.

\section{General rights}

Copyright for the publications made accessible via the Queen's University Belfast Research Portal is retained by the author(s) and / or other copyright owners and it is a condition of accessing these publications that users recognise and abide by the legal requirements associated with these rights.

Take down policy

The Research Portal is Queen's institutional repository that provides access to Queen's research output. Every effort has been made to ensure that content in the Research Portal does not infringe any person's rights, or applicable UK laws. If you discover content in the Research Portal that you believe breaches copyright or violates any law, please contact openaccess@qub.ac.uk. 
Built environment correlates of overweight and obesity among adults in Chennai, India

Deepti Adlakha ${ }^{\mathrm{a}^{*}}$, Ross C. Brownson ${ }^{\mathrm{b}, \mathrm{c}}$, J. Aaron Hipp ${ }^{\mathrm{d}}$

${ }^{a}$ School of Natural and Built Environment, Queen's University Belfast, United Kingdom

${ }^{b}$ Prevention Research Center in St. Louis, Brown School at Washington University in St. Louis, Missouri, United States of America

${ }^{c}$ Division of Public Health Sciences, Alvin J. Siteman Cancer Center, School of Medicine, Washington University in St. Louis, Missouri, United States of America

${ }^{\mathrm{d}}$ Department of Parks, Recreation, and Tourism Management, Center for Geospatial Analytics, North Carolina State University, Raleigh, North Carolina, United States of America

*Corresponding author

Email: d.adlakha@qub.ac.uk

\begin{abstract}
Overweight and obesity are steadily rising in South Asia, the world's most populous region. Recent estimates suggest that two out of every five South Asian adults are either overweight or obese. India, a low- and middle-income country in South Asia is experiencing an obesity epidemic. Built environment features may profoundly influence physical activity and counter the risk from overweight and obesity. This cross-sectional study investigated built environment correlates of overweight and obesity among adults $(\mathrm{N}=370,47.2 \%$ female, mean age $=37.9$ years) in Chennai, India. Participants from low-socioeconomic status households were more likely to be overweight/obese (odds ratio $[\mathrm{OR}]=1.8,95 \%$ confidence interval $[\mathrm{CI}]=1.1-2.9$ ) than participants from high- socioeconomic status households. Driving to work predicted a three-fold increase in overweight or obesity compared to active commuting $(\mathrm{OR}=2.9,95 \% \mathrm{CI}=1.3-6.4)$. Household car ownership was linked with an increased likelihood of overweight or obesity $(\mathrm{OR}=1.5,95 \% \mathrm{CI}=0.7-3.2)$. Low walkability neighbourhoods significantly predicted an increase in odds of overweight or obesity $(\mathrm{OR}=1.8,95 \% \mathrm{CI}=1.1-2.8)$. By 2030, Indian cities are projected to add 250 million people accompanied by a $9.9 \%$ annual motor vehicle growth rate, with substantial health and socioeconomic implications. As car ownership increases across Southern Asia, there is an urgent need to develop interventions to promote physical activity.
\end{abstract}




\section{Introduction}

The increasing prevalence of overweight and obesity continues to be a major public health concern globally. ${ }^{1}$ According to recent global estimates, more than 1.9 billion adults aged 18 years and older were overweight in 2016, and of these, over 650 million adults were obese. ${ }^{2}$ Obesity and overweight are risk factors for a range of health problems, including cardiovascular disease, stroke, type-2 diabetes, hypertension, and some cancers. ${ }^{3-5}$ South Asia, the world's most densely populated geographical region that is home to one-quarter of the world's population (nearly 1.9 billion), is facing an obesity crisis with recent estimates suggesting that two out of every five adults in the region are either overweight or obese. ${ }^{6}$ Once considered a high-income country problem, overweight and obesity are now on the rise in low- and middle-income countries, particularly in urban settings, even as they continue to struggle with a burden of infectious disease. ${ }^{7-9}$

India, a low- and middle-income country located in South Asia and the second-most populous country in the world is witnessing an obesity epidemic where the prevalence of overweight and obesity along with other non-communicable diseases has been rising steadily. ${ }^{10}$ The Chennai Urban-Rural Epidemiology Study determined that the age-standardized prevalence of generalized obesity in an adult population was $45.9 \%$ (95\% CI: 43.9-47.9). ${ }^{11}$ In another study, the prevalence of obesity among an urban adult population was 55.5\% (95\% CI: 47.2-63.4), indicating a high burden of disease. ${ }^{12}$ A comparative study across three Indian states found the prevalence of generalized obesity ranged from $11.8 \%$ to $33.6 \% .{ }^{13}$ A comparison of two major studies conducted by the National Family Health Survey in 1998-1999 and in 2005-2006 highlighted that the prevalence of obesity among Indian women elevated from $10.6 \%$ to $12.6 \%$. $^{14}$

The pace at which obesity prevalence has grown at the population level across the globe points to social and environmental causes. This sum of influences that the surroundings, opportunities, or prevailing conditions of life have on promoting weight gain and obesity in individuals or populations characterises certain environments as more 'obesogenic' than others. Obesogenic environments are characterised by increasing urbanization, use of mechanized transport, increased television viewing, adoption of less physically active lifestyles, and rise in sedentary (sitting) time. ${ }^{15}$ Calls to address the global epidemic of obesity by the World Health Organization have recommended increasing physical activity as a key strategy, highlighting the role of the built environment to support physical activity as a central focus area. ${ }^{16}$ Neighbourhoods that are activity-friendly depend upon an appropriate integration of land-use and transportation infrastructure, including higher residential densities, and street connectivity. ${ }^{17}$ The availability of pedestrian, bicycling, and transit infrastructure such as sidewalks, crosswalks, bicycle lanes, and access to public transport services (e.g., bus rapid transit, light rail) has been linked with increased levels of ttransport-related physical activity. ${ }^{18}$

A number of studies from Australasia, Europe, North America, and South America have documented positive associations between walkable, mixed-use, transit-accessible neighbourhoods and individuals' levels of physical activity and healthy weight status compared with those living in automobile-dependent neighbourhoods. ${ }^{17}$ Findings from existing studies do not lend themselves easily to generalization in other parts of the world, particularly the South Asia region that is home to over 24 percent of the world's population and at high risk of developing obesity. ${ }^{19,20}$ Although these studies show a consistent correlation between neighbourhood built environment and the prevalence of obesity in developed countries, these relationships have not been examined in India. The objective of the current study was to examine built environment correlates of overweight and obesity among adults in the city of Chennai, India. 
This study recruited a diverse sample of participants $(\mathrm{N}=370)$ from Chennai city (164.5 sq. miles, population=7.09 million), capital of the state of Tamil Nadu in southern India.

Tamil Nadu is the most urbanized state in India with $48.4 \%$ of the population living in urban areas $^{21}$ and has the highest number of diabetic cases, a majority of them reported in Chennai. ${ }^{22}$ The city has also seen a 24-fold increase in motorized vehicles in the last 10 years with private automobiles now constituting $55 \%$ of daily all-person trips. ${ }^{23}$ For administrative purposes, the Chennai metropolitan area is divided into 155 smaller subdivisions called wards, which were were the primary unit of sampling in this study. Wards the smallest geographic areas for which the Census Bureau of India publishes demographic information (compare to US census tracts). ${ }^{24}$ The Institutional Review Board of (removed for peer review) approved all study procedures.

\section{Sampling and Recruitment}

Study protocols were based on the recommendations of the International Physical activity and the Environment Network (IPEN; www.ipenproject.org). ${ }^{25}$ Participants were recruited through purposive sampling from wards stratified by walkability and socioeconomic status, to maximize variance and enhance the representativeness of the sample as low-income populations tend to be underrepresented in studies of this nature. ${ }^{26,27}$

Inclusion and exclusion criteria were based on IPEN protocol and studies conducted in Africa, Brazil and China. ${ }^{28-32}$ Eligibility criteria for participants included: (i) current residents of Chennai; (ii) residents for at least 6 months; (iii) 18-65 years of age; (iv) able to answer questions in English or Tamil; (v) not having any disability that prevented independent walking; and (vi) no visible signs of cognitive impairment. One individual per household was recruited to ensure independence of observations. Sample size was determined using a moderate-to-large effect size (effect size $[\mathrm{d}=] 0.75$ ), which is greater than what has been used previously IPEN studies in low- and middle-income country contexts such as Africa, Brazil, and China. ${ }^{28-32}$

\section{Measures \\ Neighbourhood Walkability}

The Neighbourhood Environment Walkability Scale-India (NEWS-India) was used to assess built environment features of participants' home neighbourhoods. NEWS-India consists of 91 items grouped into the following subscales: (a) residential density, (b) land use mix-diversity, (c) land use mix-access, (d) street connectivity, (e) infrastructure for walking/bicycling, (f) aesthetics, (g) traffic safety, and (h) safety from crime. Four-point Likert-type scale responses for all items ranging from 1 (strongly agree) to 4 (strongly disagree) were combined as "agree" (strongly agree, agree) and "disagree" (disagree, strongly disagree). NEWS-India items were positively scored to ensure that a higher score represented an activity-supportive neighbourhood. ${ }^{33}$ Test-retest reliability of NEWS-India has been previously established, with intra-class correlation coefficients higher than 0.75 , indicating excellent reliability. ${ }^{25}$

\section{Physical Activity}

Two modules of the International Physical Activity Questionnaire-Long Form (IPAQ-LF) were used to measure participants' leisure and travel physical activity. ${ }^{34}$ IPAQ-LF is a self-report measure that captures the frequency and duration of walking, moderate-intensity, and vigorousintensity physical activity. It has been tested internationally with reliability (Spearman's rho $\sim 0.8$ ) and criterion validity (median rho $\sim 0.3$ ) comparable to other self-reported validation studies. ${ }^{35}$ Following World Health Organization recommendations, adults aged 18-64 years should engage in 150 minutes of moderate-intensity aerobic activity in a week to incur health benefits. In the context of daily, family, and community activities, this can include leisure time 
activity (e.g., walking, dancing, gardening, hiking, swimming) or transportation (e.g., walking, bicycling). ${ }^{36}$

\section{Weight Status (BMI)}

Self-reported height and weight data was elicited from participants. Body mass index (BMI) was calculated as body weight divided by the square of height $\left(\mathrm{kg} / \mathrm{m}^{2}\right)$. The World Health Organization principal cutoff points for BMI were used to create the categories: underweight $(<$ $\left.18.5 \mathrm{~kg} / \mathrm{m}^{2}\right)$, normal weight $\left(18.5-24.99 \mathrm{~kg} / \mathrm{m}^{2}\right)$, overweight $\left(25-24.99 \mathrm{~kg} / \mathrm{m}^{2}\right)$, and obese $(\geq 30$ $\left.\mathrm{kg} / \mathrm{m}^{2}\right) .{ }^{37}$

\section{Demographic Variables}

Self-reported data on participants' age, gender, marital status, educational level, employment status, and household socioeconomic status was recorded using validated scales. ${ }^{38}$ Household socioeconomic status was measured using a validated composite scale developed for India. This scale measures three variables, namely, education, occupation of the head of the household, and income of the family. ${ }^{39}$

\section{Data Analysis}

Multiple logistic regression models were used to examine the factors associated with overweight or obesity. Models were adjusted for age, gender, household socioeconomic status, and motor vehicle ownership to control for the confounding effects of these variables as shown in similar studies conducted in low- and middle-income countries. ${ }^{40}$ Analysis was conducted using the Statistical Package for the Social Sciences (SPSS) v.25.41

\section{Results}

Descriptive characteristics of the sample population are presented in Table 1 . The mean age of the sample was 37.9 years. The majority of participants were women $(54.2 \%)$, married $(61.2 \%)$, employed (62.5\%), with a graduate or professional degree $(49.7 \%)$. Nearly half $(48.2 \%)$ of the participants reported earning less than 600 US Dollars (approximately 36,017 Indian rupees) per month.

\section{Table 1. Characteristics of the study population}

\begin{tabular}{lr} 
Descriptive Characteristics & Statistic \\
\hline Age (in years), mean (SD) & $37.9(15.3)$ \\
Gender, n (\%) & \\
Female & $199(53.8)$ \\
Male & $166(44.9)$ \\
Missing & $5(1.4)$ \\
Marital Status, n (\%) & \\
Married & $226(61.1)$ \\
Not married & $143(38.6)$ \\
Missing & $1(0.3)$ \\
& \\
Educational Level, n (\%) & \\
Uneducated & $48(13.0)$ \\
Primary-middle school & $57(15.4)$ \\
High school or diploma & $79(21.4)$ \\
Graduate or professional & $184(49.7)$ \\
\hline
\end{tabular}




\section{Employment Status, n (\%)}

Unemployed

Blue collar

White collar

Missing

$\begin{array}{lr}\begin{array}{l}\text { Monthly Family Income [in US Dollars] n (\%) } \\ \leq 80\end{array} & 74(20.0) \\ 81-200 & 43(11.6) \\ 201-549 & 24(6.5) \\ \geq 550 & 152(41.1) \\ \text { Missing } & 77(20.8)\end{array}$

\section{Household Socioeconomic Status *, n (\%)}

Low

High

Note: 1 US Dollar = approximately 65.69 Indian Rupees (average currency exchange rate, January-April 2015)

*Socioeconomic status classification and cut-off values are from a validated composite scale developed for India. The scale measures three variables - education, occupation of the head of the household, and income of the family - that are relevant to the Indian context. ${ }^{39}$

Anthropometric characteristics of participants by gender and income are presented in Table 2 . Compared to high-socioeconomic status households, a higher number of participants from lowsocioeconomic status households were overweight $(n=54,25.4 \%)$ and obese $(n=31,14.6 \%)$. Women were more likely to be obese $(n=31,15.6 \%)$ than men.

Table 2. Anthropometric characteristics of participants by gender and income

\begin{tabular}{|c|c|c|c|c|c|}
\hline \multirow{2}{*}{$\begin{array}{c}\text { Body Mass Index } \\
\text { Categories }^{1} \\
\text { n (\%) }\end{array}$} & \multirow{2}{*}{ Overall } & \multicolumn{2}{|c|}{ Gender } & \multicolumn{2}{|c|}{ Household Income } \\
\hline & & Male & Female & Low & High \\
\hline Underweight & $35(9.5)$ & $8(4.8)$ & $27(13.6)$ & $9(4.2)$ & $26(16.6)$ \\
\hline Normal weight & $177(47.8)$ & $92(55.4)$ & $84(42.2)$ & $107(50.2)$ & $70(44.6)$ \\
\hline Overweight & $77(20.8)$ & $37(22.3)$ & $39(19.6)$ & $54(25.4)$ & $23(14.6)$ \\
\hline Obese & $47(12.7)$ & $15(9.0)$ & $31(15.6)$ & $31(14.6)$ & $16(10.2)$ \\
\hline Missing & $34(9.2)$ & $14(8.4)$ & $18(9.0)$ & $12(5.6)$ & $22(14.0)$ \\
\hline
\end{tabular}

${ }^{1}$ The World Health Organization principal cut-off points for BMI were used to create the categories: underweight $\left(<18.5 \mathrm{~kg} / \mathrm{m}^{2}\right)$, normal weight $\left(18.5-24.99 \mathrm{~kg} / \mathrm{m}^{2}\right)$, overweight $(25-$ $\left.24.99 \mathrm{~kg} / \mathrm{m}^{2}\right)$, and obese $\left(\geq 30 \mathrm{~kg} / \mathrm{m}^{2}\right) .{ }^{37}$

Table 3 shows BMI, moderate-to-vigorous physical activity and sedentary levels across walkability categories. Moderate-to-vigorous physical activity was higher in neighbourhoods with higher residential density (Mean=254.8 $\mathrm{min} /$ week, $\mathrm{SD}=350.4 \mathrm{~min} /$ week), land-use $\mathrm{mix}$ diversity (Mean=251.8 min/week, $S D=486.1 \mathrm{~min} /$ week), street connectivity (Mean=231.6 $\mathrm{min} /$ week, $\mathrm{SD}=318.9 \mathrm{~min} /$ week) and safety from traffic (Mean=256.2 $\mathrm{min} / \mathrm{week}, \mathrm{SD}=448.4$ $\mathrm{min} /$ week). Numbers of overweight or obese participants were lower in neighbourhoods with higher residential density $(\mathrm{n}=54,29.7 \%)$, land-use mix diversity $(\mathrm{n}=22,25.0 \%)$, walking and cycling infrastructure $(n=19,28.4 \%)$ and safety from traffic $(n=32,28.3 \%)$. 
Table 3. BMI, moderate-to-vigorous physical activity and sedentary levels observed at walkability categories

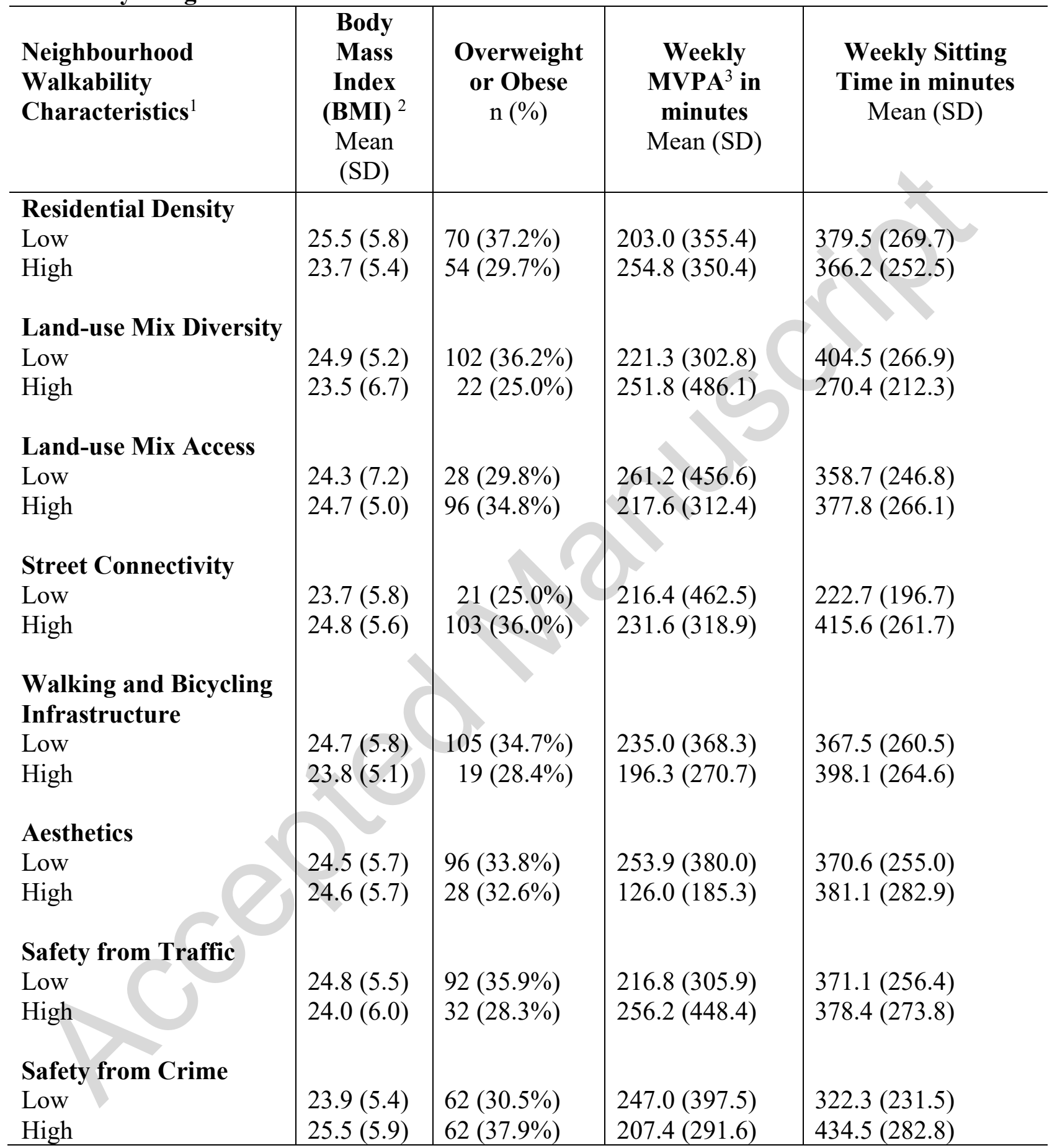

Note: ${ }^{1}$ All subscales were positively scored to ensure that a higher score denoted a more activityfriendly neighbourhood. All subscales were dichotomized. Residential density was dichotomized into low (weighted mean $\leq 545$ ) and high (weighted mean $>545$ ) densities. Land use mixdiversity was dichotomized into $\leq 10 \mathrm{~min}$ or $\geq 10 \mathrm{~min}$ walking distance. Four-point Likert-type scale response options for all other subscales (land use mix-access, street connectivity, walking and bicycling infrastructure, aesthetics, safety from traffic, and safety from crime) ranging from 1 (strongly agree) to 4 (strongly disagree) were combined as "agree" (strongly agree, agree) and "disagree" (disagree, strongly disagree)

${ }^{2} \mathrm{SD}=\mathrm{Standard}$ Deviation 
${ }^{3}$ MVPA $=$ Moderate-to-Vigorous Physical Activity

Participants from households of low-socioeconomic status were more likely to be overweight/obese $(\mathrm{OR}=1.8,95 \% \mathrm{CI}=1.1-2.9)$ than participants from households of highsocioeconomic status. Active commuting was associated with reduced likelihood of overweight or obesity compared to driving to work $(\mathrm{OR}=2.9,95 \% \mathrm{CI}=1.3-6.4)$, but this relationship did not remain significant in adjusted models $(\mathrm{aOR}=2.6,95 \% \mathrm{CI}=0.7-9.3)$. Household car ownership was associated with an increase in the likelihood of overweight or obesity $(\mathrm{aOR}=1.5,95 \% \mathrm{CI}=0.7$ 3.2) although this relationship was not significant. In unadjusted models, a low walkability neighbourhood significantly predicted an increase in odds of overweight or obesity $(\mathrm{OR}=1.8$, $95 \% \mathrm{CI}=1.1-2.8)$, but this was not significant in adjusted models $(\mathrm{OR}=1.7,95 \% \mathrm{CI}=0.9-2.9)$.

Table 4. Factors associated with overweight or obesity

\begin{tabular}{|c|c|c|c|c|c|c|c|c|c|c|}
\hline Factor & OR & $95 \% \mathrm{CI}$ & p-value & $\begin{array}{l}\text { B } \\
\text { value }\end{array}$ & $\begin{array}{l}\text { Pseudo } \\
\mathbf{R}^{2}\end{array}$ & $\mathbf{a O R}^{*}$ & $95 \%$ CI & p-value & $\begin{array}{l}\text { B } \\
\text { value }\end{array}$ & $\begin{array}{l}\text { Pseudo } \\
\mathbf{R}^{\mathbf{2}}\end{array}$ \\
\hline $\begin{array}{l}\text { Age (Ref: } 18-35 \\
\text { years) } \\
>35 \text { years }\end{array}$ & 3.0 & $1.9-4.7$ & 0.000 & 1.1 & 0.1 & $\mathrm{n} / \mathrm{a}$ & $\mathrm{n} / \mathrm{a}$ & $\mathrm{n} / \mathrm{a}$ & $\mathrm{n} / \mathrm{a}$ & $\mathrm{n} / \mathrm{a}$ \\
\hline $\begin{array}{l}\text { Gender (Ref: } \\
\text { Female) } \\
\text { Male }\end{array}$ & 1.2 & $0.8-1.9$ & 0.4 & 0.2 & 0.0 & $\mathrm{n} / \mathrm{a}$ & $\mathrm{n} / \mathrm{a}$ & $\mathrm{n} / \mathrm{a}$ & $\mathrm{n} / \mathrm{a}$ & $\mathrm{n} / \mathrm{a}$ \\
\hline $\begin{array}{l}\text { Household socio- } \\
\text { economic status } \\
\text { (Ref: High) } \\
\text { Low }\end{array}$ & 1.8 & $1.1-$ & 0.01 & 0.6 & 0.0 & $\mathrm{n} / \mathrm{a}$ & $\mathrm{n} / \mathrm{a}$ & $\mathrm{n} / \mathrm{a}$ & $\mathrm{n} / \mathrm{a}$ & $\mathrm{n} / \mathrm{a}$ \\
\hline $\begin{array}{l}\text { Household } \\
\text { car/motor vehicle } \\
\text { ownership (Ref: } N c \\
\text { Yes }\end{array}$ & 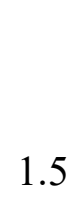 & $0.7-3.2$ & 0.3 & 0.4 & 0.0 & $\mathrm{n} / \mathrm{a}$ & $\mathrm{n} / \mathrm{a}$ & $\mathrm{n} / \mathrm{a}$ & $\mathrm{n} / \mathrm{a}$ & $\mathrm{n} / \mathrm{a}$ \\
\hline $\begin{array}{l}\text { Distance to work } \\
\text { (Ref: Distance }<= \\
10 \mathrm{~km}) \\
\text { Distance }>10 \mathrm{~km}\end{array}$ & 1.1 & $0.6-2.1$ & 0.8 & 0.1 & 0.0 & 0.7 & $0.4-1.5$ & 0.4 & -0.3 & 0.2 \\
\hline $\begin{array}{l}\text { Use public transit } \\
\text { to commute to } \\
\text { work } \\
\text { (Ref: Yes) } \\
\text { Car Driving }\end{array}$ & 1.1 & $0.6-2.3$ & 0.7 & 0.1 & 0.0 & 0.7 & $0.3-1.8$ & 0.5 & -0.3 & 0.2 \\
\hline $\begin{array}{l}\text { Actively commute } \\
\text { to work (Ref: Yes) } \\
\text { Car Driving }\end{array}$ & 2.9 & $1.3-6.4$ & 0.008 & 1.1 & 0.1 & 2.6 & $0.7-9.3$ & 0.1 & 1.0 & 0.2 \\
\hline $\begin{array}{l}\text { Public transit stop } \\
\text { within 10-minute } \\
\text { walk (Ref: Yes) } \\
\text { No transit stop }\end{array}$ & 0.5 & $0.3-0.9$ & 0.01 & -0.6 & 0.0 & 0.6 & $0.3-1.3$ & 0.2 & -0.4 & 0.2 \\
\hline
\end{tabular}




\begin{tabular}{|c|c|c|c|c|c|c|c|c|c|c|}
\hline $\begin{array}{l}\text { Meeting physical } \\
\text { activity } \\
\text { recommendations }{ }^{1} \\
\text { (Ref: Yes) } \\
\text { No }\end{array}$ & 1.1 & $0.7-1.8$ & 0.7 & 0.1 & 0.0 & 0.9 & $0.5-1.7$ & 0.8 & -0.1 & 0.2 \\
\hline $\begin{array}{l}\text { Time spent sitting } \\
\text { weekly } \\
\text { (Ref: Low, }<=60 \\
\text { minutes/day) } \\
\text { High }\end{array}$ & 1.2 & $0.8-1.9$ & 0.5 & 0.2 & 0.0 & 1.2 & $0.7-2.0$ & 0.6 & 0.1 & 0.2 \\
\hline $\begin{array}{l}\text { Neighbourhood } \\
\text { walkability score } \\
\text { (Ref: High) } \\
\text { Low }\end{array}$ & 1.8 & $1.1-2.8$ & 0.01 & 0.6 & 0.0 & 1.7 & $0.9-2.9$ & 0.07 & 0.5 & 0.2 \\
\hline
\end{tabular}

Note: Note: $\mathrm{OR}=$ Unadjusted Odds Ratios, $\mathrm{aOR}=$ Adjusted Odds Ratios, $\mathrm{CI}=$ Confidence Interval

${ }^{1}$ At least 150 minutes of physical activity per week based on global recommendations for physical activity among adults established by the World Health Organization

\section{Discussion}

This study is one of the first to explore neighbourhood environment correlates of obesity and overweight among urban residents in India. Impacts of the physical and social environment on obesity and overweight have been examined in recent epidemiological literature, however there is a paucity of research on the environmental correlates of obesity from South Asia, despite a significant portion of the obesity disease burden being concentrated in the region. ${ }^{42-45}$ We found that walkable neighbourhoods were associated with higher levels of physical activity and lower odds of obesity/overweight. Residents living in neighbourhoods with a diversity of destinations, availability of walking and bicycling facilities were more likely to meet physical activity recommendations. Active commuting was associated with lower odds of being overweight or obese. These results raise the possibility that built environment attributes found to facilitate active commuting in higher-income countries do not fully generalize to low- and middle-income countries. Findings from this study in urban India emphasize the need for more high-quality epidemiologic studies from low- and middle-income countries.

In our analyses, driving to work predicted a three-fold increase in overweight or obesity compared to active commuting in unadjusted models, but this relationship did not remain significant in adjusted models. Previous studies have highlighted that active commuting could reduce the detrimental effect of obesity and could potentially decrease the risk of premature mortality. ${ }^{46,47}$ Research has also shown that residents in walkable, activity-friendly neighbourhoods, such as well-connected streets, tree-shaded sidewalks, pleasant aesthetic features, and transit access have higher levels of active commuting and a lower prevalence of obesity. ${ }^{17}$ Active commuting is specifically associated with improved physical fitness, weight control, reduced cardiovascular risk, and lower obesity. ${ }^{47}$ Despite these benefits, urban India is witnessing inadequate development of public transport infrastructure, hazardous conditions for walking and bicycling, and a mass adoption of private motorized vehicles. ${ }^{21,48-50}$

Previous research from India has highlighted that urban living is associated with lower transport physical activity and increasingly sedentary lifestyles. ${ }^{51}$ All of these factors are likely contributing to declining levels of active commuting and a rise in population prevalence of overweight, obesity, and related non-communicable diseases in India. This is important given that India's urban planning models lack suitable policies to manage growth, ${ }^{52}$ which has resulted 
in urban sprawl and traffic congestion, made worse by inadequate quality and safety of public transport and non-motorised transport infrastructure. ${ }^{53}$ As Indian cities expand and car ownership increases, pedestrians are being marginalised and their safety is likely being put at risk.

Studies have suggested that variations in physical activity and obesity prevalence may be driven by income or education, although patterns might differ across countries. Previous studies on associations between socioeconomic status and obesity concluded that obesity was essentially a disease of the socioeconomic elite in low- and middle-income countries, in contrast to the situation in developed countries where obesity was more common among the poor than among the rich ${ }^{54}$ However, recent research has shown that the burden of obesity is shifting toward the poor in developing societies. ${ }^{55}$ Findings from this study confirmed this trend with participants from low-socioeconomic status households more likely to be overweight or obese. There are multiple individual and environmental factors that may explain why populations in neighbourhoods of low-socioeconomic status are less active and bear greater obesity burdens. One reason may be that parks, green spaces and playgrounds are less available to people living in poor neighbourhoods, thereby limiting opportunities for physical activity. ${ }^{56}$ Low-income populations may be less able to afford indoor exercise equipment and/or memberships to gyms, sports facilities, and recreation centres. Neighbourhoods with higher poverty rates also tend to experience higher levels of crime and violence, which can deter physical activity. ${ }^{57}$

Socioeconomic characteristics are associated with physical activity levels, and this is especially true of car ownership. In this study, motor vehicle ownership demonstrated a strong association with obesity and overweight in unadjusted models, which confirms previous research. Findings from low- and middle-income countries like Mexico, Colombia, and Nigeria, have shown that motor vehicle ownership is inversely associated with transport-based physical activity and a predictor of obesity. ${ }^{58-60}$ Studies have shown that non-vehicle owners tend to have higher levels of transport-based physical activity levels, which may be strongly driven by necessity rather than choice. As automobile ownership increases across the developing world and has become the primary mode of transportation, the built environment has evolved such that walking, bicycling, and other forms of active travel are difficult and even hazardous. ${ }^{61}$ More research is needed to understand and assess socio-economic factors and their relationship with active commuting across larger geographical areas and over extended periods of time in low- and middle-income country contexts in South Asia.

\section{Strengths and Limitations}

The cross-sectional study design limits causal inference and the relatively small sample from a single city in India may restrict generalizability of these results. Further, the possibility of residual confounding and self-selection (i.e., individuals who prefer active lifestyles may select to live in areas that are more conducive to walking, bicycling, and active travel modes) are limitations of this study. Self-reported measures such as IPAQ and NEWS are prone to bias from social desirability, recall period, sampling approach, or selective recall. ${ }^{62}$

In recent studies, researchers have independently weighed and measured participants to calculate BMI and used accelerometers to track physical activity. These methods can provide objective data, however, self-reported anthropometric data are commonly used to estimate prevalence of obesity in population and community-based studies of this nature. ${ }^{63}$ A key limitation of studies in this area is a lack of consensus on the measurement of physical activity domains and types of activity in each domain, reliability and validity of questionnaires to measure domain-specific physical activity, and the inability to compare results across studies due to the large number of measures available. ${ }^{64}$ This study did not investigate the relationship between dietary patterns and body weight, which may be a key factor contributing to the risk of overweight and obesity in 
Indian populations. Studies have investigated links between consumption of high glycaemic diets and susceptibility to obesity, diabetes, and non-communicable diseases in some regions of India, however, the findings are mixed. ${ }^{65}$ Despite the limitations, this study fills a critical gap in the scientific literature to resolve the problematic and urgent implications for population physical activity and public health in an urban South Asian context.

\section{Conclusions}

As the global burden of disease shifts from infectious diseases to non-communicable diseases in South Asia, an understanding of how environmental factors affect obesity, and how best to influence them is important for public health, health equity, and urban planning. By 2030, Indian cities are projected to be home to another 250 million people alongside a $9.9 \%$ annual growth rate in motor vehicles. The health and socio-economic implications from this heavy reliance on motorised transportation are likely to be substantial, running into tens of billions of dollars every year. ${ }^{61,66}$ Similar patterns of rapid urban growth and motorised traffic are being witnessed across South Asia and potential concerns with respect to declining physical activity levels, reduced road safety, worsening air pollution, and traffic congestion. Low- and middle-income countries in South Asia have a particularly high reliance on private automobiles compared to other parts of the world, with higher rates of car usage and ownership reported in Indonesia, Cambodia, the Philippines and Vietnam. ${ }^{67}$

As car ownership increases across South Asia, extra efforts may be needed to ensure population levels of physical activity. The documented harms of high automobile use such as lung diseases from air pollution, higher non-communicable disease risk due to the inactivity during vehicle use, and injury and death from traffic crashes, must be considered. ${ }^{68,}{ }^{69}$ Building infrastructure that supports active commuting and equitable transit access can promote physical activity. ${ }^{17}$ City planners, public health practitioners, and elected officials need to design policies and programs that reach all members of society, especially the poor. Designing walkable communities may enable people at all income levels to travel to work, to school, and for daily needs using active transport modes. Walkable, activity-friendly neighbourhoods can also enable people with longdistance work commutes to reduce non-work automobile travel that increases non-

communicable disease risk. ${ }^{17,70}$ It is also important for future studies in South Asia to investigate the role of diet, nutrition, and physical activity in order to achieve the best results in preventing non-communicable diseases. Systematic attention to measuring social, cultural, and built environments could lead to improved understanding of their role in enhancing or inhibiting physical activity and the development of context-specific interventions to increase population levels of physical activity.

\section{Acknowledgements}

**Removed for peer review**

\section{References}

1. Jaacks LM, Vandevijvere S, Pan A, McGowan CJ, Wallace C, Imamura F, et al. The obesity transition: stages of the global epidemic. The Lancet Diabetes \& Endocrinology 2019;7(3):231-240.

2. Guthold R, Stevens GA, Riley LM, Bull FC. Worldwide trends in insufficient physical activity from 2001 to 2016: a pooled analysis of 358 population-based surveys with 1.9 million participants. The Lancet Global Health 2018;6(10):e1077-e1086.

3. Beaglehole R, Bonita R, Horton R, Adams C, Alleyne G, Asaria P, et al. Priority actions for the non-communicable disease crisis. The Lancet 2011;377(9775):1438-1447.

4. Guh DP, Zhang W, Bansback N, Amarsi Z, Birmingham CL, Anis AH. The incidence of co-morbidities related to obesity and overweight: a systematic review and meta-analysis. BMC Public Health 2009;9:88. 
5. Lauby-Secretan B, Scoccianti C, Loomis D, Grosse Y, Bianchini F, Straif K. Body Fatness and Cancer--Viewpoint of the IARC Working Group. N Engl J Med 2016;375(8):794-8. 6. Helble M, Francisco K. The Upcoming Obesity Crisis in Asia and the Pacific: First Cost Estimates. ADBI Working Paper 743. Tokyo: Asian Development Bank Institute.; 2017. 7. Prentice AM. The emerging epidemic of obesity in developing countries. International Journal of Epidemiology 2006;35(1):93-99.

8. Swinburn BA, Sacks G, Hall KD, McPherson K, Finegood DT, Moodie ML, et al. The global obesity pandemic: shaped by global drivers and local environments. Lancet 2011;378(9793):804-14.

9. Siddiqui ST, Kandala NB, Stranges S. Urbanisation and geographic variation of overweight and obesity in India: a cross-sectional analysis of the Indian Demographic Health Survey 2005-2006. Int J Public Health 2015;60(6):717-26.

10. Meshram, II, Vishnu Vardhana Rao M, Sudershan Rao V, Laxmaiah A, Polasa K. Regional variation in the prevalence of overweight/obesity, hypertension and diabetes and their correlates among the adult rural population in India. Br J Nutr 2016;115(7):1265-72. 11. Deepa M, Pradeepa R, Rema M, Mohan A, Deepa R, Shanthirani S, et al. The Chennai Urban Rural Epidemiology Study (CURES)--study design and methodology (urban component) (CURES-I). J Assoc Physicians India 2003;51:863-70.

12. Rautela YS, Reddy BV, Singh AK, Gupta A. The prevalence of obesity among adult population and its association with food outlet density in a hilly area of Uttarakhand. J Family Med Prim Care 2018;7(4):809-814.

13. Pradeepa R, Anjana RM, Joshi SR, Bhansali A, Deepa M, Joshi PP, et al. Prevalence of generalized \& abdominal obesity in urban \& rural India--the ICMR-INDIAB Study (Phase-I) [ICMR- NDIAB-3]. Indian J Med Res 2015;142(2):139-50.

14. Garg C, Khan SA, Ansari SH, Garg M. Prevalence of obesity in Indian women. Obes Rev 2010;11(2):105-8.

15. Mackenbach JD, Rutter H, Compernolle S, Glonti K, Oppert J-M, Charreire H, et al. Obesogenic environments: a systematic review of the association between the physical environment and adult weight status, the SPOTLIGHT project. BMC public health 2014;14:233-233.

16. World Health Organization. Global Recommendations on Physical Activity for Health; 2019.

17. Sallis JF, Cerin E, Kerr J, Adams MA, Sugiyama T, Christiansen LB, et al. Built Environment, Physical Activity, and Obesity: Findings from the International Physical Activity and Environment Network (IPEN) Adult Study. Annual Review of Public Health 2020;41(1):119-139.

18. Kerr J, Emond Jennifer A, Badland H, Reis R, Sarmiento O, Carlson J, et al. Perceived Neighborhood Environmental Attributes Associated with Walking and Cycling for Transport among Adult Residents of 17 Cities in 12 Countries: The IPEN Study. Environmental Health Perspectives 2016;124(3):290-298.

19. Milton K, Macniven R, Bauman A. Review of the epidemiological evidence for physical activity and health from low- and middle-income countries. Global Public Health 2014;9(4):369-81.

20. Elshahat S, O’Rorke M, Adlakha D. Built environment correlates of physical activity in low- and middle-income countries: A systematic review. PLOS ONE 2020;15(3):e0230454.

21. Ministry of Urban Development (MOUD). Level of Urbanization. New Delhi, India: Government of India; 2013. 
22. Gupta S, Singh Z, Purty A, Kar M, Vedapriya D, Mahajan P, et al. Diabetes prevalence and its risk factors in rural area of Tamil Nadu. Indian Journal of Community Medicine 2010;35(3):396-399.

4 23. Government of Tamil Nadu. Vehicular Position in Chennai City as on 1.3.2014.

5 Chennai, India: State Transport Authority; 2014. India: Government of India; 2011.

25. Adlakha D, Hipp JA, Brownson RC. Adaptation and Evaluation of the Neighborhood Environment Walkability Scale in India (NEWS-India). International Journal of Environmental Research and Public Health 2016;13(4).

26. Turrell G. Income non-reporting: implications for health inequalities research. J Epidemiol Community Health 2000;54(3):207-14.

27. Cerin E, Conway TL, Saelens BE, Frank LD, Sallis JF. Cross-validation of the factorial structure of the Neighborhood Environment Walkability Scale (NEWS) and its abbreviated form (NEWS-A). International Journal of Behavioral Nutrition and Physical Activity 2009;6(1):32.

28. Oyeyemi AL, Kasoma SS, Onywera VO, Assah F, Adedoyin RA, Conway TL, et al. NEWS for Africa: adaptation and reliability of a built environment questionnaire for physical activity in seven African countries. Int J Behav Nutr Phys Act 2016;13(1):33.

29. Cerin E, Conway TL, Cain KL, Kerr J, De Bourdeaudhuij I, Owen N, et al. Sharing good NEWS across the world: developing comparable scores across 12 countries for the Neighborhood Environment Walkability Scale (NEWS). BMC Public Health 2013;13:309. 30. Salvo D, Reis RS, Sarmiento OL, Pratt M. Overcoming the challenges of conducting physical activity and built environment research in Latin America: IPEN Latin America. Preventive Medicine 2014;69 Suppl:S86-S92.

31. Oyeyemi AL, Sallis JF, Deforche B, Oyeyemi AY, De Bourdeaudhuij I, Van Dyck D. Evaluation of the neighborhood environment walkability scale in Nigeria. International Journal of Health Geographics 2013;12:16.

32. Saelens BE, Sallis JF, Black JB, Chen D. Neighborhood-based differences in physical activity: an environment scale evaluation. Am J Public Health 2003;93:1552 - 1558.

33. Kerr J. Advancing science and policy through a coordinated international study of physical activity and built environments: IPEN adult methods. J Phys Act Health 2013;10(4):581-601.

34. IPAQ. International physical activity questionnaires. IPAQ-long: last 7 days selfadministered format. In: International physical activity questionnaires; 2002.

35. Craig CL, Marshall AL, Sjostrom M. International physical activity questionnaire: 12country reliability and validity. Med Sci Sports Exerc 2003;35(8):1381 - 1395.

36. World Health Organization. Global Recommendations on Physical Activity for Health. In: Global Strategy on Diet, Physical Activity and Health. Geneva: World Health Organization; 2010.

37. World Health Organization. Obesity: Preventing and Managing the Global Epidemic. WHO Technical Report Series 894 2000. Geneva, Switzerland: World Health Organization; 2000.

38. Bairwa M, Rajput M, Sachdeva S. Modified Kuppuswamy's Socioeconomic Scale: Social Researcher Should Include Updated Income Criteria, 2012. Indian J Community Med 2013;38(3):185-186.

39. Gururaj, Maheshwaran. Kuppuswamy's Socio-Economic Status Scale - A Revision of Income Parameter For 2014. International Journal of Recent Trends in Science And Technology 2014;11(1).

40. Kerr J, Emond JA, Badland H, Reis R, Sarmiento O, Carlson J, et al. Perceived Neighborhood Environmental Attributes Associated with Walking and Cycling for 
Transport among Adult Residents of 17 Cities in 12 Countries: The IPEN Study. Environ Health Perspect 2016.

41. IBM Corp. IBM SPSS Statistics for Windows, Version 25.0. In. Armonk, NY: IBM Corp.; Released 2012.

42. Bassett DR, Jr., Pucher J, Buehler R, Thompson DL, Crouter SE. Walking, cycling, and obesity rates in Europe, North America, and Australia. J Phys Act Health 2008;5(6):795814.

43. Bauman AE, Reis RS, Sallis JF, Wells JC, Loos RJF, Martin BW. Correlates of physical activity: why are some people physically active and others not? The Lancet 2013;380(9838):258-271.

44. Becerra JM, Reis RS, Frank LD, Ramirez-Marrero FA, Welle B, Arriaga Cordero E, et al. Transport and health: a look at three Latin American cities. Cadernos de Saúde Pública 2013;29:654-666.

45. Heath GW, Parra DC, Sarmiento OL, Andersen LB, Owen N, Goenka S, et al. Evidencebased intervention in physical activity: lessons from around the world. The Lancet 2012;380(9838):272-281.

46. Gordon-Larsen P, Nelson MC, Beam K. Associations among Active Transportation, Physical Activity, and Weight Status in Young Adults. Obesity Research 2005;13(5):868875.

47. Yang L, Hipp JA, Adlakha D, Marx CM, Tabak RG, Brownson RC. Choice of commuting mode among employees: Do home neighborhood environment, worksite neighborhood environment, and worksite policy and supports matter? Journal of Transport \& Health 2015;2(2):212-218.

48. Ministry of Road Transport and Highways. Basic Road Statistics of India. In: Ministry of Road Transport and Highways; 2010-2011.

49. Pucher J, Zr P, Mittal N, Zhu Y, Korattyswaroopam N. Urban transport trends and policies in China and India: impacts of rapid economic growth. Transport Reviews 2007;27. 50. Solanki HK, Ahamed F, Gupta SK, Nongkynrih B. Road Transport in Urban India: Its Implications on Health. Indian Journal of Community Medicine : Official Publication of Indian Association of Preventive \& Social Medicine 2016;41(1):16-22.

51. Adlakha D, Hipp JA, Brownson RC. Neighborhood-based differences in walkability, physical activity, and weight status in India. Journal of Transport \& Health 2016;3(4):485499.

52. Mohanty PK. Cities and Public Policy: An Urban Agenda for India. SAGE Publications; 2014.

53. Chatterjee A, Chattopadhyay RN. Satellite Towns in Neo-metropolitan Development in India: Lessons from Selected Cities. Springer Singapore; 2020.

54. Ogden CL, Fakhouri TH, Carroll MD, Hales CM, Fryar CD, Li] X, et al. Prevalence of Obesity Among Adults, by Household Income and Education — United States, 2011-2014. MMWR Morb Mortal Wkly Rep 2017;66:1369-1373.

55. Monteiro CA, Conde WL, Popkin BM. Income-specific trends in obesity in Brazil: 1975-2003. American journal of public health 2007;97(10):1808-1812.

56. Sallis JF, Slymen DJ, Conway TL, Frank LD, Saelens BE, Cain K, et al. Income disparities in perceived neighborhood built and social environment attributes. Health Place 2011;17(6):1274-83.

57. Rees-Punia E, Hathaway ED, Gay JL. Crime, perceived safety, and physical activity: A meta-analysis. Preventive Medicine 2018;111:307-313.

58. Oyeyemi AL, Ishaku CM, Oyekola J, Wakawa HD, Lawan A, Yakubu S, et al. Patterns and Associated Factors of Physical Activity among Adolescents in Nigeria. PLoS One 2016;11(2):e0150142. 
59. Salvo D, Torres C, Villa U, Rivera JA, Sarmiento OL, Reis RS, et al. Accelerometerbased physical activity levels among Mexican adults and their relation with sociodemographic characteristics and BMI: a cross-sectional study. Int J Behav Nutr Phys Act 2015;12:79.

60. Parra DC, Lobelo F, Gomez LF, Rutt C, Schmid T, Brownson RC, et al. Household motor vehicle use and weight status among Colombian adults: are we driving our way towards obesity? Prev Med 2009;49(2-3):179-83.

61. Shoham DA, Dugas LR, Bovet P, Forrester TE, Lambert EV, Plange-Rhule J, et al. Association of car ownership and physical activity across the spectrum of human development: Modeling the Epidemiologic Transition Study (METS). BMC public health 2015;15:173-173.

62. Wood TM. Issues and Future Directions in Assessing Physical Activity: An Introduction to the Conference Proceedings. Research Q for Exerc Sport 2000;71(2):ii-iv. 63. Bowring AL, Peeters A, Freak-Poli R, Lim MS, Gouillou M, Hellard M. Measuring the accuracy of self-reported height and weight in a community-based sample of young people. BMC medical research methodology 2012;12:175-175.

64. Steele R, Mummery K. Occupational physical activity across occupational categories. J Sci Med Sport 2003;6(4):398-407.

65. Joy EJ, Green R, Agrawal S, Aleksandrowicz L, Bowen L, Kinra S, et al. Dietary patterns and non-communicable disease risk in Indian adults: secondary analysis of Indian Migration Study data. Public health nutrition 2017;20(11):1963-1972.

66. Adlakha D, Hipp JA, Sallis JF, Brownson RC. Exploring Neighborhood Environments and Active Commuting in Chennai, India. Int J Environ Res Public Health 2018;15(9).

67. The Organisation for Economic Co-operation and Development. Economic Outlook for Southeast Asia, China and India 2019 Towards Smart Urban Transportation: Towards Smart Urban Transportation. OECD Publishing; 2018.

68. Douglas MJ, Watkins SJ, Gorman DR, Higgins M. Are cars the new tobacco? Journal of Public Health 2011;33(2):160-169.

69. Giles-Corti B, Vernez-Moudon A, Reis R, Turrell G, Dannenberg AL, Badland H, et al. City planning and population health: a global challenge. The Lancet 2016;388(10062):2912-2924.

70. Vancampfort D, Smith L, Stubbs B, Swinnen N, Firth J, Schuch FB, et al. Associations between active travel and physical multi-morbidity in six low- and middle-income countries among community-dwelling older adults: A cross-sectional study. PloS one 2018;13(8):e0203277-e0203277. 